\title{
The Upgraded Democracy Adjusted for the 21 Century
}

\author{
Amos Avny \\ Omnidev International, Yehud, Israel \\ Email:amosav@smile.net.il
}

How to cite this paper: Avny, A. (2019). The Upgraded Democracy Adjusted for the $21^{\text {st }}$ Century. Open Journal of Philosophy, 9, 223-235.

https://doi.org/10.4236/ojpp.2019.92015

Received: April 22, 2019

Accepted: May 19, 2019

Published: May 22, 2019

Copyright $\odot 2019$ by author(s) and Scientific Research Publishing Inc. This work is licensed under the Creative Commons Attribution International License (CC BY 4.0).

http://creativecommons.org/licenses/by/4.0/
Republic: "A State in which supreme power is held by the people and their elected representatives." Democracy: "A system of government by the whole population or all the eligible members of a state, typically through elected representatives."

\begin{abstract}
The author examines how does Democracy, the leading form of government in the world, fit itself to the tremendous changes occurred in the world toward the $21^{\text {st }}$ Century. Technology causes many changes that frequently occur before people and their organizations are able and competent to digest them. The author suggests some techniques and models for assisting nations to carry out the initiative of revising and enhancing their running systems. The article uses for the analysis of a two-aspect technique, constructed of Philosophical and Psychological methods for promoting understanding. Thus, the Philosophical aspect represents the Brain-the Rational way of thinking while the Psychological approach represents the inner-self feelings-the Emotional tactic toward actual occurrences. By using these two complimentary approaches, the picture accepted and the knowledge accumulated are much more completed and relevant.
\end{abstract}

\section{Keywords}

Democracy, Capitalism, Freedom, Wealth, Freezing, Philosophy, Psychology, Economic, Social Sciences and Government

\section{Introduction}

In the concluding conclusion of a previous paper, we claim that: "At the second decade of the $21^{\text {st }}$ Century, while the Post-modern approach recruits more and more supporters, it is time to examine and rethink many of the former ${ }^{1}$ Oxford Dictionaries. 
methodologies" (Avny, 2018). The forms of government, both, Democracy and Republic and how they fit themselves to the Post-modern reality, are among the subjects that should be examined. The main difference between our time and the former days lays in the fact that more citizens are aware of the governance process, more relevant information is available to them as they seek a more meaningful involvement in this process. The dramatic breakthrough of technology and the massive effect of the information democratization process, are the two main factors promoting the above change. Unfortunately, not too many university schools, of all disciplines, really are attuned to these changes and even less dare to offer some reasonable solutions. The result is a worldwide confusion or as we have paraphrased President George Bush in 1989, we face "a New World Disorder". This "disorder" is well demonstrated by the anti-establishment voting for President Donald Trump in US, and by the Brexit vote in UK. President Trump's proclamation of "America First", which contradicts clearly the capitalist statement of "Free Market", is another example of the irrelevancy of the former terms.

Thousand years ago, Republic and Democracy were offered by the ancient Greeks as formations describing an unautocratic regime that is run by the people and for the people. Although the two terms are very similar, some differences can be noted.

"The key difference between a democracy and a republic lies in the limits placed on government by the law, which has implications for minority rights. Both forms of government tend to use a representational system, i.e. citizens vote to elect politicians to represent their interests and form the government' (Wikipedia).

Another, quite a simple distinction is that a democracy could be both a republic - ruled by the people, and a monarchy_ruled by a king. While a republic, by definition, cannot be governed by a single monarch or an autocratic dictator.

Thousand years had passed through since the ancient Greeks had discussed democracy. Beside UK, little happened in the rest of the world, until the $18^{\text {th }}$ Century, when the great French Revolution and the drafting of the American Constitution, had made the form of government relevant again.

At first quarter of the $20^{\text {th }}$ Century, authoritative approach became popular due to the illusions and the promises of the dictatorial regimes like the Communism, the Nazism and the Fascism. Two World Wars had to pass until the Western Nations realized how much they needed exercise a real functioning liberal democracy. This process was completed with the end of the Cold War, the final collapsing of the Communist Block and the end of the de-colonization era, at the end of the $20^{\text {th }}$ century. The World had then faced a new reality, as proclaimed by President George Bush-“a New World Order”. However, these hopes unfortunately disappeared and the World eventually faced "a new world disorder" - in other words, some kind of a Chaos.

[Despite the visible wealth and the consuming prosperity, there are still 
many unhappy people. They have material achievement but suffer from spiritual and intangible deficiency. In their search for happiness, they face many obstacles. It is the purpose of a work like this to point out in a promising way for a better future. It is an important mission, necessary for pursuing new avenues with potential prosperity and happiness.]

\section{Contemplations on Today's Society}

On the eve of the $20^{\text {th }}$ Century, Democracy became the most popular and dominant form of government in the world. This process was accompanied by a Technological unprecedented break-through. Due to these two significant moves, people all over the globe feel today liberated and free to look for more satisfied life. Hopes, wishes and inspirations grew unproportionally high while their expressions were amplified even higher. It is obvious that when wishes replace needs the rational limits are thrown away. Consequently, many of the former arrangements, agreements, understandings, rules and regulations are becoming obsolete or irrelevant. The daily challenges rapidly increase while answers and solutions are limping behind. Keen observations on people conduct indicate that with this freedom comes a move from rationality to a more emotional behavior. Such a move is also supported by a sense of relative affluence, which envelops many of today's societies. Although economists tend to associate human decision with rational choice and claim that people preference emerges from logical choices, this argument is irrelevant today. At present, many are driven by their emotions instead of being directed by their brain. The Britons decision to leave the European Union (EU), a harmful decision by all means, and Europeans resist against foreign immigrants, who contribute significantly to their economy, are only two demonstrating examples for this reality. Democracy and Technology change the political agenda of today. Satisfying constituent wishes and desires, rather than fulfilling its needs is the new mission of today's regimes. This simple but significant change can also be described as moving from the modern framework of meeting countable necessities to undefinable acts of satisfying indescribable desires. It is like a move from an Orderly world toward a Chaotic environment.

One of the outcomes, emerged from this change, is the diminishing state and strength of the Political Parties. As said, the ideological distinction between the major main-stream parties is fading out because all of them contains members with similar views. It is reasonable to assume that they agree about $80 \%$ of the issues and differ only about the remaining $20 \%$. The best and more convicting test for proving such an argument is examining the Government annual budget, which should reflect it view and programs of the state policy. Such test well demonstrates that little differences can be found between the Democrats and the Republicans or between the Conservatives and the Labor. This prevailing actual political reality reduces the status of the Political Parties as an ideological light house or a conceptual compass for the party members. Thus, Affiliation with a 
political party, in the $21^{\text {st }}$ Century, in many Nations, became a matter of inner self preferences, family heritage, work-place environment and public fashion. It has little to do with the former deep ideological conviction. Resulting from this change, Political Leaders and Social Activists, who run for a public position or seek a seat in the parliament, must be aware of these significant changes. They, must learn to evoke emotions and speak to their constituent's hearts. Those who fail to do this properly, deserve falling, because they are too rational and use wrong logical communication (Avny, 2016).

The emergence of a different nature of the political constituent, since they are more emotional than rational, and the decreasing stand of the conventional political parties, emerge from the lessening interest of the general public in politics. Thus, it leads to examine the traditional parliament two-sides set-up of Coalition and Opposition. Another factor that should be taken into consideration is the rapid growing number of radical and extreme fractions that care less about tradition and democracy. It is necessary, therefore to seek ways for detaching them from influential positions. One of our favorite way is the building of "The Grand Coalition" constructed of the two or three largest parties. Such an initiative may ensure the work of government, made it more steady, stable and effective. This practice is maintained for some decades in Germany and proved to be the most successful example. The idea of converting an opponent into a partner may be revolutionary, but this is what the new Post-modern Era demands. Moreover, such a meaningful change should also affect the nature and capacities of many politicians. They should decrease a little their public appearances and dramatic proclamations while trying hard improving their covert negotiation capacities, their coalition building skills and consistency striving for silently achieving benefits for their interest groups. Converting a political exhibitionist into a confident and reliable negotiator is not an easy undertaking, but that is what is required from the new political leaders.

Critical Thinking, Open Mind-ness, Imaginary Contemplations and Devoted Consistency, are the critical building-blocks required for establishing the revised model of democracy. The application of such a suggestion depends, of course, on every Nation while the "pros" and the "cons" should carefully be examined. But the potential benefits are high and the foreseen risks are small. Gaining such a National Unity is a very promising gift and it can affect the wealth and prosperity of both the country and its citizens.

For further understanding the complexity of the situation it is necessary to go back in time for examining the roots and the origins of the contemporary practices. The Ancient Greeks, when referring to Republic as a form of government, meant basically to the Masters-since they are those who are qualified for governing. Similarly, the American Founding Fathers, when drafting the Constitution, referred mainly to "Gentlemen", since women, slaves and black people were not recognized as legitimate partners. Therefore, it is fair to claim that until the $21^{\text {st }}$ Century, many citizens were practically unable to be involved in the go- 
vernance process. Moreover, up to now, it is not clear what is the exact meaning of the opening statement of the Constitution Preamble: "We the People". Who these people are? It is a general proclamation but still unclear. In the $2^{\text {nd }}$ decade of the $21^{\text {st }}$ Century one can see that people's conventional affiliation with traditional parties is decreasing. The be-partisan unclear policy about the Brexit, in UK, the election of a non-partisan person as President Cameron in France, and the vague nature of the popular movements in Italy's Government, just support this argument. Ideology in general and particular a comprehensive inclusive old-time Ideology lost its relevancy. Nobody is ready, or willing any more, to harness his/her life style and behavior to something that is irrelevant or obsolete theory.

Technology and Democracy endorse people and enabled them to be more emotional, to attune more to their open and covert wishes and to promote various dreams that were not accepted fifty years ago. The big question, and may be the key one, is: whether the Government and all other public administrative organs are ready and properly prepared for fulfilling their role in the present situation?

Additionally, and unfortunately, there are only few novel experiences to present a general perspective about political-economic system of the $21^{\text {st }}$ Century. Our, the Social-Capitalism Perspective, is among these few, while still it seeks recognition and exposure (Avny, 2016).

The dramatic advancement of technology had changed this situation. It provides a variety of sophisticated smartphone devices, which enable everyone to receive much information, at all time and immediately. Similarly, a variety of private communication networks were created, which in fact, encouraged people to express themselves in almost every public or private affair. These open free lines of communication, the affluent sources of available information and the sense of personal freedom promote the wish for greater involvement in the process of ruling. Many are not satisfied with the right to vote, every 3 - 5 years and seek a more active participation role in the current process of public decision making.

On the other side, Government officials and delegates, from both branches, the Legislature and the Executive tend to oppose to these desires. It is a well-known reality, those who have the power try hard not to share it with others. Both groups, civil servants and representatives will do all they can for distancing common people, social activists and enthusiastic laypersons from participating in governance.

Another, inherent contradiction is hidden in the definition of the democracy's "People" or the "Constituent". Most works in the field wrongly interpreted "equality before the law" as a general equality. For political needs it was also preferred stating that "all people are equal", which in fact is not true. An old Jewish proverb say it quite clear: "People's soul, talents and faculties vary as their face and external appearance do". In former works we have elaborated on this point while recommending on the "Normal Distribution Theory" and the "Bell 
Type Curve" as the proper methods for studying populations (Avny, 2012). Thus, the present challenge is "how the maintain a working liberal democracy constructed of a variety of people with different wishes and aspirations"? The above question also hints on the complexity of the answer, which moves from a qualitative measure to a quantitative one. For over fifty years economists tried hard to make Economics a quantitative discipline. They have also created Econometrics as a designated field for enabling more accurate and computerized equations. It is, therefore quite ironic that the advanced technology forces scholars to return to psychology when studying human behavior.

Facing the above-mentioned challenges, Democracy, as the leading worldwide form of government, must be attuned to these changes, feelings and trends and must adjust itself to the new developments.

\section{Reflections for the Future}

Changing the nature of democracy and adjust it to the reality of the $21^{\text {st }}$ Century, like other major changes, is carried out, according to the Kurt Lew (1943) in Change Management Model. This Model is constructed of three major phases: Unfreeze, Change and Refreezing. These three phases are applied to the discussion on democracy, as follows: Phase 1. Revising the theoretical basis of democracy, Phase 2. Modifying the political practices, and Phase 3. Grounding the revised model of democracy.

\subsection{Revising the Democracy's Theoretical Basis}

This stage, the Unfreezing phase, is very important since it ignites the whole process. It may also be the toughest one since it drives the system from a passive stand-still situation into a moveable and active one. In this case, theories and writings on democracy run thousand years back. Scores of scholars and practitioners in Political Science and closed fields had wrote and taught the basic principles and guidelines of this form of government. All this teaching was carried out within a relative stable and steady environment. Many had gained their Academic status, their reputation and their prestige by presenting, describing and promoting a given, generally accepted and respected political form of government. Winston Churchill had well described it by stating: "Democracy is a complicated system but it is the best we have."

The tremendous technological change the world had passed through-out the past fifty years. The almost unlimited freedom and the vast availability of data opened today for millions, changes and increases the demand for a revised and advanced form of government. Basically, more and more citizens wish to be more active and ask for more involvement in the governing processes. They are not any more satisfied with fulfilling the passive role of voters, who leave most of the ruling activity to the representatives. In short, the former style of representative democracy, led mostly by elected delegates, does not fit any more the wishes, aspirations and desires of contemporary citizens. The mission 
for the theoreticians is, therefore, to offer, sketch and draw changes, amendments and adjusts, for making democracy more suitable, more relevant and better meeting the people's demands. Such a mission faces many hardships, since, usually, older and reputable scholars do not like to change their teaching, which granted them recognition, respect and reputation. Most writers prefer continuing their traditional heritage and proceeding within their professional track, rather than opening new avenues for novel ideas. So, the first step in this long way for transition, is recognizing that a change is needed and unavoidable. Unfreezing the dominating perspective and motivating scholars to enhance their knowledge is "all about weighing up the 'pro's' and the 'con's' and deciding if the 'pros' outnumber the 'cons' before any action is taken. This is the basis of what Kurt Lew in called the Force Field Analysis" (Wikipedia). The above analysis may indicate what are and how strong are, the factors that enforce or reject the proposed change. Since in most Social, Political or Economic organizations there are elements, which have, or have not, vested interests, they are, in essence, the roots of the change's supporters or opponents, the pros and the cons. The topics, to be reviewed, discussed and be modified are detailed below, while more may appear along the study:

\subsubsection{Examining and Improving Election Techniques}

In most cases, General Elections are carried out in a conventional manner, using voting boxes for gathering the voting tickets. Because of this, counting the votes is conducted manually and results are available after many hours. Usually some mistakes occurred during the counting and the whole system is open for doubts and even legal challenges. Moving toward the use of a more sophisticated and electronic modes faces one major problem, which is finding a reliable, indisputable and secure method for identifying the voters. Since most of the technology required for that mission is available, it is just a matter of public demand for introducing them into the election systems.

\subsubsection{Recognizing and Legitimizing the Use of Social Networks}

Social and similar networks are popular and prevailing types of communication in the world of today. The problem is that they are not recognized as such, they are free with almost no control and there are neither rules nor regulations for directing them. Since they are so popular instruments, some agency should be established for administer this field.

\subsubsection{Identification and Anonymity in Social Networks}

With all the positive contributions social networks have on democratic life and the growing amount of public involvement in politics, it also has some negative effects. The first, and maybe the worst determinant is the Anonymity option. Many will agree that enabling people to speak or write in anonymity release them from many conventional conducts and similar limitations. As known, a person's mouth is frequently his/her greatest enemy. Participation in the nameless correspondent of the social networks enhances this unpleasant communica- 
tion and increases its irresponsible manners.

For correcting this failure, networks in the future, will be evaluated and marked according their rate of identification. Full name exposure will grant the highest mark while full anonymity will remain on the bottom.

\subsubsection{Incorporating of Referendums in the Political Set-Ups}

As said, present conventional democracies suffer from citizens' decreasing involvement in political life, as is demonstrated by the lessening participation in general elections. At the same time people seek direct participation in the political decision-making process. The best way for bridging over such a contradiction is by introducing periodical referendums into the current political agenda. Although both the executive and the legislature branches seem to deny such an initiative, because it complicates their life and reduces their administrative power, this act is necessary. Some types of referendum are already exercised in Switzerland and in some of US states and no harm was caused to any of the traditional democratic practices. Thus, it seems that in the future referendums will accept their legitimate role in the revised models of democracies while the exact form will be built in accordance with every state's needs.

\subsubsection{Revising the Government 3 Branches' Relationships}

No question that the proposed change in the nature of democracy also demands improving and reshaping the relations between the three branches of government, the Legislature, Executive, and the Courts of Law. The previous balanced status, which was established two hundred years ago, and was refined over the years, deserves a renewed approach applicable to the Post-modern chaotic world. The decreasing weight of Ideologies and the growing wish of individuals to take a more active role in the process of governance are just two leading factors justifying such an act.

\subsubsection{Balancing Government Involvement in the Economy}

The former capitalist argument of clear distinction and separation between the Public and the Private sectors becomes obsolete in the $21^{\text {st }}$ Century. Not that such a separation is wrong theoretically, it is also not practical and not applicable. Moreover, the Third sector, the Non-Government Organizations, the NGOs, are becoming an indispensable part of many economies. So, the proper and realistic way to run national economies is by collaboration and practical division of responsibility between these three sectors. Government involvement in the economy is a daily fact while cooperation and working together is the best way to carry it forward. A popular method for such a functionality is what is known as "Public Private Partnership" (PPP). Enhancing the use of this technique would advance the productivity of the whole economy and will benefit all the participants, citizens, organizations, small and big businesses.

\subsubsection{Reducing Bureaucracy and Pointless Regulation}

Almost every organization, small or large, urge to expand and grow. Govern- 
ments, which are among the largest organizations on earth have naturally the same nature. Similarly, they wish to increase their control and impose their supervision. Some see positively such a tendency, as a safe-guard against corruption. This wrong approach springs mostly from a dubious atmosphere and uncertainty approach characterizes many civil servants. Although they are aware and concern of the public assets, they want also to exercise the power of control given to them. This is, in a way, a foolish interpretation of the capitalist value of "competition". Changing the former political-economic conception and installing a revised advanced model of Social-Capitalism may affect also those old-fashioned bureaucrats, convincing them to reinstate trust and responsibility within their customers. A trustworthy environment and a respectful business sphere may result with healthier society and more efficient working conditions. E-government could be one of the leading instruments for attaining this goal.

\subsubsection{Limitation of Serving on Office}

It took the Americans over one hundred and fifty years to amend the Constitution on this issue. We can just use the wording of the $22^{\text {nd }}$ Amendment for expressing our view: "No person shall be elected to the office of the President (or Prime-minister) more than twice". Historical experience indicates that longer years in such a high position may lead to unrespectful behavior and over-using of ruling power by the said individual. Such a preventing limitation yields benefits for the ruling individual and for society at large.

During the first unfreezing phase more and other themes, besides the above-mentioned ones, will appear, requiring more analyses and further study. This will be conducted by the designated teams.

The execution of these missions, or the implementation acts will lay the grounds for the revised model of democracy It will rests on the present advanced technology and matches the peoples' demand for more practical involvement in the political decision-making process. Based on prior knowledge and experience, it is assumed that this first stage will take some five to ten years, from initiation to conclusion.

\subsection{Introducing the Modified Political Proposal}

Unfortunately, it is fair to admit, that during the past decades the reputation and the social stand of politicians is deteriorating. This unfortunate trend was partly caused, because of the unproper and less-responsible behavior of some politicians. However, a great part of this degradation emerges from the citizens' renewed sense of freedom, their wish to be involved and their inspiration to find better solutions. Consequently, executing the second phase of the Change Model, the eventual Transition Process, is going to be more complicated, because of several reasons.

$\underline{\text { First, }}$ as mentioned in the third preliminary notes, even democratic Nations differs because of many reasons, such as, size, location, culture, traditions, mentality and wealth. Thus, after the general theoretical grounds were laid, another, 
more specific customer-made proposal, should be prepare for every state candidate who is interested in improving its form of democracy.

Secondly-Negotiation with the concerning groups, such as, delegates, politicians, community leaders, public-opinion specialists, etc. on the preferred ways for carrying out the transition process and implementing the proposed revised system.

It is important focusing on the benefits and rewards of the renewed system while noting the punishing hardships foreseen from neglecting or denying it.

Thirdly-This stage is also the time for pointing out on practices for ensuring government formal longevity by encouraging the creation of "a Grand Coalition" (a coalition composed of the two largest parties with a steady majority in Parliament). Such an act also may foster government efficiency by releasing it from threats and hurdles imposed by small radical groups of both sides of the political map. In Europe for example, Germany, which for decades maintain such a Grand Coalition, the regime is stable since radical fractions are distanced from government.

Italy, in contrary, where coalitional governments come and go permanently, represents the opposite version of a democratic government - a shaking, unstable and volatile system with short-time governing periods. The fact of the matter is that at present, political affiliation is less ideological and more tradition, family and communal-oriented. The difference between the two large middle parties are frequently unobservable. It is, therefore, easier today to set-up such a Grand Coalition, more than it was twenty or thirty years ago.

Fourthly-Towards the coming years, the number of retirees and other types of elderlies that permanently struggle with the e-government innovations, grows rapidly. The digital techniques, that were designed for saving time and money, frequently do not fit them. They still seek the human tough and the human officials for taking care of their problems. Government and administrative innovators and technology-oriented reformers must be aware of this growing demand and should be capable for o adjusting themselves to meet these requirements.

Fifthly-There are many other political issues, relevant to every specific country, that should be taken in account in every initiative of amending or enhancing the quality of the working system. The bodies who are going to introduce the revised model of democracy must be aware of them and should find ways for involving them in the transition process.

Carrying out this stage missions is going to be quite difficult, since it is not a theoretical undertaking, executed by Academicians and Scholars in schools of Political Sciences and Public Administrations, but rather, it is mainly the Politicians and Community Leaders' job. Usually these persons pursue the short-time assignments and frequently disregard the long-time duties. However, since the adjustment of the democratic process is not just a theoretical inspiration, but also an important social requirement, we hope that it will properly being carried out. We anticipate that it will take five to seven years until completion. 


\subsection{Grounding and Running the Revised Model of Democracy}

After laying the Theoretical Grounds, introducing the required Changes and experiencing the Transition Process, time comes for establishing and running the Revised Model of Western Democracy. Even now it should be noted that it is just a model and many adjustments should be made in order to make it suitable for functioning in different countries. These adjustments are:

1) The Population's Size-1 - 5, 8 - 20, 30 - 59, 60 - 120 million citizens and over. Comparing between nations while disregarding the size of their population is like comparing apples with oranges. The size differentiation is necessary since its referrers to many social and economic aspects and therefore also on their political et-up.

2) The type of the Regime-a State, Union or a Federation

Due to historical factors nations had built their own specific democratic systems and intend to keep them working. It is imperative that any suggestion for revision or a Change will be attuned to these small differences.

3) The Form of Government-Parliamentary, Presidential, etc.

The nature of the democratic government differs from one nation to another. Here also, as in the previous section, the change initiative should not be involved in this issue. Both, Parliamentary and Presidential systems work properly, but need some improvements. Introducing some of the proposed techniques may assist them.

\section{4) The Nation's Cultural, Customs and Traditional Heritage}

Lay-persons and scholars, politicians and economists tend mistakenly to compare and equate between nations. The actual differences between them are so complicated and spring from so many qualitative and unmeasurable causes. It is, therefore, recommended to accept the traditional nature of every nation as a basic fact and applying the proposed changes to the nation's own character.

\section{5) Other critical factors.}

The nature of the $21^{\text {st }}$ chaotic time is that nothing is certain but only the uncertainty itself. Introducing improvements and changes into such working systems is complicated by its nature. The uncertainty reality just adds some additional factors to the complicated mission. Thus, the change advocates and the transition's proponents, must take these unknown obstacles into account.

\section{Conclusion}

The main goal of the whole Change process, proposed here is to modify Democracy by making it not the only feasible form of government, but reshaping it to be the best available option for the post-modern and Digital Era of $21^{\text {st }}$ century. Following the saying that "the pudding taste is determined by its eaters", the quality of the proposed improvements depends on their proponents and executioners. Their job is not only to introduce and run the modified system but also may be mainly to see and ensure that it will function effectively and fairly. Under the Change Model's third phase title-Refreeze, a modified and 
advanced Democracy should flourish, as the best form of government for the $21^{\text {st }}$ Century.

At the opening sentences, we refer to the Philosophical and the Psychological aspects of many phenomena, claiming that they are two sides of the same coin. In fact, they assist us in better understanding events, processes and occurrences. Generally speaking, the Philosophical aspect may represent the Brain-the rational way of thinking while the psychological approach represents the inner-self feelings-the Emotional tactic toward actual occurrences. This two-aspect technique assists us also in analyzing and comprehending political affairs. Without a general philosophical observation, the main course and the political establishment goals will remain obscure and unclear. Without a psychological understanding of the participants, both leaders and followers, the motivations, drivers and human concerns will not be understood. Thus, combing the two completing techniques should be very helpful for deepening our knowledge of democracy at our time.

\section{The Author's Personal Remarks}

\subsection{Objectivity vs. Subjectivity in Social Sciences}

The Author strongly believes that little objectivity can be observed in social studies. Every scholar in this field is an intelligent human-being who have his/her own personal conscious and their own point of view.

Thus, it is quite natural that the Author, while writing this paper and presenting his observations, rests on his own perceptions.

\subsection{Misunderstanding and Mix-Up in Social Sciences}

Due to many reasons, and maybe because of lack of enough knowledge, people, laypersons and scholars, tend wrongly to seek generalities and commonalities where they are not relevant. Individual Medicine, which is the future direction of healthcare development, is a good example for proving this case. Above the basic level of public healthcare, advanced medicine is going to be prescribed specifically for a given patient's requirements.

\subsection{Specifying the Scope of the Discussion}

As said scholars tend to seek generalities. However, this is not the case in many times. As the world is divided geographically into five or six continents so world population is divided into several Civilizations (Huntington, 2003). Every civilization has its own history, heritage, customs and culture. A mistaken interpretation of the term Equality tends disregarding these authentic cultural characteristics and prefer seeing world population as one same identical mass.

We for a change, refer our writing to the Western Civilization only, which we know and are independent part of it. There are, of course, things and remarks that are relevant to other civilizations, but since we do not know them enough, we do not relate to them. 


\section{Conflicts of Interest}

The author declares no conflicts of interest regarding the publication of this paper.

\section{References}

Avny, A. (2012). How to Secure the Blessing of Liberty (pp. 29-35). Germany: LAP LAMBERT Academic Publishing.

Avny, A. (2016). Essays of a Senior Optimist (pp. 108-116). Germany: LAP LAMBERT Lambert Academic Publishing.

Avny, A. (2018). The Philosophy-Psychology Linkage. Open Journal of Philosophy, 216-224.

Huntington, S. (2003). The Clash of Civilizations (Hebrew Edition). Jerusalem: Mercaz Shalem.

Kurt, L. (1943). Defining the "Field at a Given Time". Psychological Review, 50, 292-310.

Oxford Dictionaries. 